\title{
Adapting first aid education to fragile contexts: A qualitative study
}

Ellen Gordon, Thomas Wilp, Emily Oliver, Jeffrey L. Pellegrino

Evidence for international firstaid guidelines predominantly comes from studies conducted in western contexts during peacetime and/or healthcare settings. Yet, internationally the burden of trauma falls on low-and middle-income countries where lay responders might have to act in fragile contexts, where first aid and healthcare resources arelimited or not available.

This study focuses on the principles and practices that govern firstaid education (FAE), versus clinical evidence of first aid interventions. Accepting that application of first aid may vary according to context, we sought to understand educational principles according to contextual resources of fragile and non -fragile environments.

We interviewed educators, from six countries where conflict, geography or resources deemed them to be fragile, to explore which educational approaches were used and found effective in educating potential lay responders.

Through qualitative analysis, we identified educational approaches and themes including:

- The need to take a basic (de-medicalized) approach;

- Context adaptation;

- Consideration of the types of injuries and emergencies that learners were likely to face;

- Engaging learners through active learning approaches; and

- A focus on critical thinking.

We connected a similar set of educational approaches in non-fragile contexts, as reflected in the International First Aid and Resuscitation Guidelines 2016. Recognizing common educational approaches provides educators with a common base on which to develop their educational approach and build future recommendations with global applicability. This also allows for mutual research and application between FAE in fragileand non-fragile environments.

The definition of 'fragility', according to the Organization for Economic Cooperation and Development (2016), incorporates concepts of exposure to risk with insufficient capacity to cope with those risks. As such, fragility affects a significant proportion of the global population. The World Bank (2017) identified 36 fragile situations for 2018 across the globe, whilst the Fund for Peace (2017) listed 66 countries in its lowest four categories of fragility. In these contexts, risks may be economic, environmental, political, societal or security-based. The work of the International Red Cross and Red Crescent Movement (hereafter referred to as 'the Movement') is frequently carried out in fragile contexts such as areas affected by armed conflict and/or natural disasters. Thus, the impact of fragility, and how to work effectively in these areas supports the development of the Movement's outcomes. 
First aid, a core pillar of the Movement's work, manifests differently in fragile contexts. Fragility may mean increased dangers (such as violence, risky environments, etc.) to civilians/first responders/humanitarian personnel, limited/no medical supplies, or the lack of access to emergency medical services (EMS) and healthcare facilities. Each fragile context maintains a uniqueness in proportion of risk both physically and socially. To mitigate risk and respond, the Movement's work incorporates first aid education (FAE) for lay responders to fill the gap that would be filled by state-provided pre-hospital care systems.

Traditional approaches to FAE require individuals to learn how to prevent and prepare to act in an emergency, the first domain in the Chain of Survival Behaviors (IJFAE, 2017). Emergency action then would be taken as a result of this preparation, in a context in which individuals might face additional challenges of safety and resources (the 'first aid' domain). We consider both domains relevant to effective education to enable people to apply their first aid skills and behaviors in fragile contexts. We question the reciprocity of approaches to teaching first aid between fragile or challenging contexts and non-fragile contexts to advance the practice of FAE.

\section{Context}

The International Federation of Red Cross and Red Crescent Societies (IFRC) is a constituent part of the Movement and produces the International First Aid and Resuscitation Guidelines (hereafter referred to as the Guidelines). Each guidelines topic goes through an evidence review process by experts in clinical and field based first aid; and made freely available to any actor involved in first aid across the globe, in four languages. In 2016, the Guidelines included, for the first time, a chapter on facilitating first aid education (FAE), which detailed core principles and guidance for effective and efficient learning. These principles included a focus on the learner, with particular attention to creating learning relevant to the audience and tailoring education to learner objectives. Recommendations included that curriculum and pedagogy be engaging and provide an environment for learners to demonstrate their new skills, behaviors, or knowledge. Content should be varied according to learner needs, and multiple learning modalities should be utilized in order to ensure the education is accessible and relevant to all (Sarak \& Ok, 2010; Lippmann, Livingstone \& Craike, 2011). Universally available, the Guidelines' authors wrote explicitly for curriculum designers, with a caveat that the recommendations be appropriately applied for individual (local to national) contexts.

The work of the International Committee of the Red Cross (ICRC), another constituent part within the Movement, specifically operates in conflict situations with a strong focus on trauma first aid. The Guidelines' authors highlighted the work of the ICRC as a potential area of digression for Guidelines implementation. The Guidelines note that practices recommended may not always be possible in the contexts where the ICRC operates and advises the implementation of local practices if appropriate.

This study focuses on the principles and practices that govern FAE and not on the clinical evidence of first aid interventions. Whilst accepting that application of first aid may vary according to context, we sought to understand whether educational principles should also vary according to contextual resources of fragile and non-fragile contexts.

\section{Literature Review}

Research demonstrates a positive impact of increasing emergency response capacity through FAE (Husum, Gilbert, Wisborg, Van Heng, \& Murad, 2003, and Murad \& Husum, 2010). Collectively, these authors document that prehospital trauma systems can reduce mortality rates in trauma victims, highlighting the life-saving role first aid can play. These studies were all conducted in low- and middle-income countries (LMICs), many of which also meet the criteria for fragility. Increasing the intention to help (Miller \& Pellegrino, 2018) of those who are often able to respond in the absence of any professional assistance is an approach which can be used to mitigate the impact of fragile health systems. To this end, the World Health Organization (WHO) recognizes the need to equip lay person first 
responders and recommends this as part of its guide to emergency medical systems in LMICs (Kobusingye, Hyder, Bishai, Hicks, \& Mock, 2005). Henry \& Reingold (2012) piloted a first aid course in Kampala, Uganda and recorded $97 \%$ of participants using at least one skill they learnt on the course in the following six months.

We did not identify any literature specifically on educational approaches to FAE in a fragile context. Further insight into the most effective methods to educate and equip people to deliver first aid interventions would help fill this gap. Such work also supports the research agenda articulated by the Fogarty International Centre of the National Institutes of Health (2008) explicitly identified the need to tailor interventions to local conditions in LMICs. Tailoring interventions and approaches to delivery in local conditions is practical in fragile contexts, because the factors limiting healthcare would most likely affect education resources too. More than just limited resources, limited time and urgent needs put pressure on learners and educators to be efficient and effective. FAE studies noted in the Guidelines, as well as International Liaison Committee on Resuscitation (ILCOR) (2015) Consensus on Science and Treatment Recommendations, assessed either classroom or public health campaign outcomes neglecting FAE in fragile contexts.

To conceptualize the gaps in first aid and FAE (Oliver, Pellegrino, \& Freshour, 2016), the Chain of Survival Behaviors (IJFAE, 2017) identified five domains that link to increase individual and population survival rates. The first domain of 'prevention and preparedness' is an essential step in the process before the most effective first aid can be delivered. It is the most overlapping domain and accounts for the need to put the others into action when appropriate. The Guidelines suggest that tailoring interventions to local conditions considers the need to adequately prepare people for situations they may encounter immediately in fragile contexts or within a lifetime.

\section{Scope}

The FAE provided by the Movement seeks to increase the capacity of first aid in all communities. As to the methods and philosophies of FAE, different contexts may utilize different approaches because of variation in time, resources, populations (want or need education), and local contexts. We sought to explore the following questions through a qualitative study of first aid educators in fragile contexts:

- What principles or approaches do educators in fragile contexts use to ensure their education is effective?

- Are the education principles expressed in the International First Aid Guidelines (2016) applicable to fragile contexts?

- Are people being educated in a way that enables them to deal with real-life first aid situations, outside of the controlled learning environment of a first aid course?

\section{Methods}

We employed a constructivist approach to collect experiences and describe the realities of FAE in fragile contexts from the perspective of Movement's educators (Guba \& Lincoln, 1994, Charmaz, 2000, \& Bryant, 2002). Building on the idea that people create their own subjective versions of reality, the study aimed to explore these multiple realities to identify whether any common themes or patterns linked these separate experiences and interpretations.

Four Movement staff members involved in first aid, including a first aid delegate currently deployed in a fragile context contributed to the development of the guiding interview questions. Six questions then structured each interview, to explore the experience of participants (see Table 1), all individuals who could provide in-depth insight into

FAE in fragile contexts based on their experience. The interviewer followed up with clarifying questions based these six questions to ascertain further insight.

\section{Sample}

The study population consisted of staff members of either the ICRC or IFRC National Societies, with experience of working in fragile contexts, and being first aid educators. We recruited participants through established links with the ICRC, 
Table 1: Guiding Questions for Interviews

\begin{tabular}{|c|c|c|}
\hline Question & Focus & Question wording \\
\hline 1. & $\begin{array}{l}\text { Adaptation to } \\
\text { local contexts }\end{array}$ & $\begin{array}{l}\text { How you do adapt your FAE to local contexts? E.g. role play, use of non- } \\
\text { medical equipment, story-telling? } \\
\text { a. How do you work with local practices to make sure FAE is } \\
\text { relevant and useable to the local population? }\end{array}$ \\
\hline 2. & $\begin{array}{l}\text { Measuring } \\
\text { success }\end{array}$ & How do you measure the success of the education activities you run? \\
\hline 3. & $\begin{array}{l}\text { Impact of low- } \\
\text { resource setting }\end{array}$ & $\begin{array}{l}\text { What impact do environments with no/few resources or with difficulties } \\
\text { in accessing healthcare have on your FAE activities? }\end{array}$ \\
\hline 4. & $\begin{array}{l}\text { Confidence } \\
\text { building activities }\end{array}$ & $\begin{array}{l}\text { What do you do to make sure that people feel confident to use First Aid } \\
\text { in a situation where they don't have resources or where it is difficult for } \\
\text { them to get to the people who need help? (e.g. confidence-building } \\
\text { activities, discussions...) }\end{array}$ \\
\hline 5. & $\begin{array}{l}\text { Repeated } \\
\text { training }\end{array}$ & $\begin{array}{l}\text { How often do you repeat training for different groups of people? Please } \\
\text { give an explanation of why you repeat courses and the impact this has } \\
\text { on people's learning. }\end{array}$ \\
\hline 6. & $\begin{array}{l}\text { First aid and local } \\
\text { health facilities }\end{array}$ & $\begin{array}{l}\text { Do health facilities (e.g. hospitals, trauma centers) in your area record } \\
\text { casualties who have been given first aid before they arrive? (This } \\
\text { question was asked in an effort to understand level of external reliance } \\
\text { on and interest in application of first aid by third parties). }\end{array}$ \\
\hline
\end{tabular}

following attendance at a week-long training workshop, held in Geneva, Switzerland, in September 2016. Five participants were first aid delegates/leads responsible for coordinating and delivering FAE on behalf of their institution (either the ICRC or a National Society of the Red Cross/ Red Crescent). Two additional participants (who had not been present at the workshop) were recommended by ones that were present at the workshop. These participants were subsequently invited by email.

The total sample $(\mathrm{n}=7)$ worked in South America (SA), North Africa (NA) (3), Central Africa (CA), Asia (A), and Eastern Europe (EE). We report direct quotations using these geographical initials to maintain confidentiality. All participants directly engaged first aid learners that included lay people, various professional groups, state and non-state armed groups, first responders, and National Red Cross and Red Crescent Society volunteers.

We informed each participant of the aims and purpose of the study and voluntary participation in a detailed letter and received internal approval from their supervisors. Interview responses were de-identified by the interviewer (EG) to ensure participants felt able to answer openly. Ethical guidance was sought from Geneva University Ethics Board which determined the study did not fall within the spectrum of the Law on Human Research as defined in Article 2 (Switzerland).

\section{Data collection}

Participants were interviewed in English, using a semi-structured approach by the primary researcher, via Skype with video, each lasting 
approximately an hour. As English was not the first language of any participant the video format allowed for non-verbal communication and mutually validated comprehension of questions and answers.

The interviewer (EG) recorded responses using a mix of verbatim quotes and paraphrased notes. Participants verified all quotations to ensure accuracy. EG verbally repeated back paraphrased ideas or concepts which were noted down, to interviewees as written down to reduce the likelihood of misinterpretation on the part of the interviewer.

\section{Analysis}

We used a pragmatic thematic analysis (Braun and Clarke, 2012) to code the data, by reading each transcript several times to identify recurring concepts or experiences, to generate initial codes. We then searched these concepts and experiences for any broad themes into which they could be grouped. Once we identified themes, we re-read all the transcripts to code segments of text into each theme. Post analysis, we invited and discussed the coded themes with key stakeholders from the Movement to check for their fit within the field of FAE. The discussions centered on the interpretation of the data recorded in the transcripts and assignment to specific themes.

\section{Findings}

We identified five themes connected to the question of effective FAE principles in fragile contexts. These are: a 'basic' approach; context adaptation; audience adaptation; active learning and critical thinking.

\section{1-A 'Basic' Approach}

References to complicated procedures and the use of medical terminology were seen negatively by many of the educators. They referenced the need to keep training simple in terms of content and educational methods, particularly for audiences not familiar with clinical language/settings.
Basic for me means the essential simple procedures which can be explained to and applied by all people everywhere...no special equipment...no sophisticated procedures. (NA)

\section{2-Context Adaptation}

Context adaptation generally related to the need for the educator be able to adapt first aid content in response to key cultural norms to create or maintain credibility with learners. This demonstrated a shared responsibility by the educators as part of their role. For one educator, the need to be aware of and refer to local guidelines used by the military and the police force is vital when working with that population. Learners "become skeptical" (EE) if the educator was unaware of these guidelines/practices.

...it needs to be a joint project with the people

from that culture. (NA)

Don't get them (learners) to imagine something

they haven't seen for themselves. (NA)

\section{3-Audience Adaptation}

Adaptation to audience required educators to consider the types of injuries and emergencies that learners were likely to face, and to take this into account in terms of course content. In one example, a community audience received training on how to deal with domestic injuries, such as burns, whereas a course for hospital porters, who often are required to give first aid, focused on injuries from weapons. In another context, scenarios were changed for a military audience whose aim was not necessarily to only preserve life, but to ensure any wounded soldier was able to continue in their task. Adapting to audiences does not just apply to content adaptation, but also included audience attributes, like literacy levels. An example of this was a context where written knowledge questionnaires or text-based resources were inappropriate, necessitating the use of verbal debriefing sessions.

For some educators, asking the learners to create the scenarios in which they practice first aid skills became a crucial way of ensuring the learners' 
experiences and contexts were central to the session. Incorporating learners' prior experiences into education is about "teach(ing) according to the community emergencies" (SA) as opposed to imposing an external understanding of what is needed. Educators reported challenges with regards to incorporating learner interests/ experiences into FAE. In a low-resource setting in Africa, learners wanted training on how to use defibrillators as they had seen similar training in a Western context. This was despite their location having very few/no defibrillators available for use.

\section{4-Active Learning}

Active learning, an umbrella term for an approach that seeks to engage the learner in the learning process through participation, came through unanimously as each educator incorporated scenarios into their FAE. Educators developed scenarios to address skills, such as stopping bleeding, from a local context. For example, in violence-prone fragile contexts a shooting scenario would be used. Learners worked together with the educator to create the storyline and the setting. Learners then collaborated on developing a response with the observation and support of the educator. They acted the scenario out taking on the roles of the injured person, any bystanders, responders, weapons bearers etc. Educators facilitated feedback from learners on how scenarios were dealt with from first aid and social perspectives. It was clear that these educators saw the clinical response to an injury or illness not as the sole focus, but inclusive of the overall management of the emergency, including personal safety and dignity for the person in need of assistance.

Situating the approach firmly within an active learning methodology, one educator referred to the need to "never kill an idea" (NA). If a learner suggests an action which may not be suitable, educators encouraged group discussion. Learners arrived at a solution themselves, without relying on the educator to do it for them.
It (scenarios) changes the atmosphere...people are more interested and engaged. (NA)

\section{5-Critical Thinking}

A focus on critical thinking and giving learners the tools to respond to whatever situation they may encounter emerged as a common thread throughout all the interviews. The purpose of education for all the educators interviewed was not only to impart knowledge, but to give people the skill to think for themselves about how to apply that knowledge outside of the learning environment. One participant described creating differing scenarios for learners in order to test their ability to adapt to different situations.

Trainpeople how to think, not how to do. (CA)

It's about how creative you are with what you

know, not just about first aid skills. (NA)

It's not just bandages; teach that the point is to

stop bleeding with whatever you have. (NA)

\section{Discussion}

Each theme resonated in each interview providing a level of consensus, which may due to the educators belonging to the Movement, and thus subscribing to a shared set of principles. Similarities across their experiences and, potentially, a shared language used to express those experiences can be expected to some extent. Whilst membership of the Movement may account for some degree of consensus between participants, their experiences were diverse in fragile contexts that included conflict, lack of access to healthcare, and environmental challenges. Educators represented different environments, countries, cultures, and learner populations. This suggests that there are some principles and approaches to education which can be applied effectively in a diverse range of fragile contexts. The themes therefore provide a level of evidence to respond to the first research question of principles or approaches used by educators in fragile contexts that were effective from their perspective. Other principles or approaches might be used in fragile contexts, and the themes 
identified in this paper are not necessarily exhaustive. The themes provide an insight into the development considerations for FAE.

We address the second research question, regarding how principles expressed in the Guidelines apply to fragile contexts, from expert consensus. The qualitative evidence of the interviews supports the recommendations within the Guidelines, which positions first aid as a humanitarian action which can be done by anyone; although no interviewee provided any reference to the Guidelines themselves. (EO \& JP were coordinating authors of the Education chapter in the Guidelines.)

Theme 1: a 'basic' approach manifested as a demedicalized approach to first aid. Educators avoided using medical terminology where possible and aimed to make the actions as simple as possible for learners to follow and apply. The Guidelines promote this approach as necessary to meet learning outcomes. Each clinical topic in the Guidelines contains an Implementation Considerations' section to support curriculum/ educator design needs and contextual application. This basic approach may position first aid within a pro-social helping behaviors framework, whilst more traditional approaches to FAE may position the intervention within a more clinical or certification arena. The clinical Guidelines were never intended for verbatim use in FAE and need to be understood by Trainer of Trainers and local educators but adapted for final use.

Themes 2-4 combine to engage learners socially, psychologically, and physically, and connect to the engaged approach to learning, with space given for learners to demonstrate their new skills, knowledge and behaviors. Active participation of learners and educators in the experience appeared to be of central focus for what educators deemed as effective strategies. The active learning described by the educators manifested most frequently as scenario-based learning, which is a recommendation from the guidelines (IFRC, 2016, p. 37). Scenario-based learning with peer feedback enhances the level of engagement from learners, requiring them to evaluate the actions of others and themselves, during reflection and feedback; an approachused in the education arena more generally to extend learning (Kolb, 1984; McNeil et al, 2006).

The collective experience of first aid educators in fragile contexts provides partial insight into the final research question as to whether the FAE provided enables learners to deal with real-life first aid situations outside of the controlled learning environment of a first aid course. All the educators reported that they only assessed FAE through knowledge and skills assessments. Assessments typically were done informally, through educators/peer learners watching and commenting on learner responses to potential situations, as in scenario-based activities with learners demonstrating their response through drama. The lack of recorded outcome measures means that it is not possible to analyze the extent to which learners are enabled to respond to reallife first aid situations. The educators did share an awareness of the need to impress upon learners the realities of first aid situations outside of the learning environment. The active learning strategies used, and scenario-based learning, are examples of educators seeking to equip learners to respond to challenging circumstances.

Theme 5: the critical thinking element identified in the interviews also plays a crucial role in this process of equipping learners for real-life situations. Educators were clear that enabling learners to think for themselves and adapt to a range of situations was of paramount importance due to the fragile contexts in which they lived. Audience and context adaptation helped bring relevancy and focus on preparing learners for situations they were likely to encounter.

\section{Implications}

The findings from this study suggest that principles of education expressed by the Guidelines, which draw their evidence base from studies operating in non-fragile contexts (such as 
Kato, Suzuki \& Hori, 2012; and Lippmann, Livingstone \& Craike, 2011), are congruent with the educational approaches arising from the experience of educators interviewed in this study, educating in fragile contexts. Whilst the manifestations of those approaches will likely change depending on the context, there is no evidence to suggest that the principles themselves should change. This implies that learning from situations of entrenched or reoccurring fragility could be applied to non-fragile contexts, and vice versa. These findings should help to provide evidence for a unified principles-based approach to education for the next iteration of the Guidelines and development of first aid educators inside and outside fragile contexts.

Activities based on the educational principles identified in this and tested in fragile and nonfragile contexts should seek to measure learning outcomes that affect the likelihood of a learner being able to use their skills effectively in whatever circumstance they face. This would enable an analysis of which approaches truly make an impact on learner behaviors in first aid situations, deepening the body of evidence as to what constitutes effective FAE.

\section{Limitations}

Due to recruitment occurring primarily at the workshop referred to above, this is a convenience sample and limiting to generalizability outside of the Movement. Not all ICRC first aid delegates were in attendance and only those who expressed an interest were emailed with participation details. Some of those in attendance at the workshop operate in fragile contexts but are employed by a National Society rather than the ICRC. Due to these constraints, the sample cannot be considered representative of the overall population of first aid educators working in fragile contexts.

Technical difficulties, in part due to the geographic location of participants, meant that it was not possible to record the interviews. Answers were therefore transcribed in real time by the researcher although repetition was used to ensure accuracy of transcription. Due to budget and language constraints of researchers, only participants with a proficient level of spoken English were included in the study; and only one researcher was involved in the interviewing and transcribing the interviews (EG).

These limitations, combined with the small sample size $(\mathrm{n}=7)$, prevent this study from being generalizable to all FAE in fragile contexts, but provides a foundation for future research.

\section{Conclusion}

Similar sets of educational principles apply to FAE in both fragile and non-fragile contexts. Acknowledging the similarities and how they apply from a general educational approach to the specific of fragile context provides educators and developers with a common base upon which to build future FAE guidance and recommendations across the Movement and with other training organizations working across different fragile contexts (such as disaster, war, migration) and is an indication that a common core of FAE could be crafted with global applicability, and empowerment of first aid educators to recognize, address, or use those contextual factors to meet learning outcomes. The findings also highlight the need to collect data on effectiveness of FAE, in the form of outcome measures, in order to provide a moreinformed view of what truly makes FAE effective. 


\section{References}

Braun, V. \& Clarke, V. (2012) Thematicanalysis. In H. Cooper, P. M. Camic, D. L. Long, A. T. Panter, D. Rindskopf, \& K. J. Sher (Eds), APA handbook of research methods in psychology, Vol. 2: Research designs: Quantitative, qualitative, neuropsychological, and biological (pp. 57-71). Washington, DC: American Psychological Association.

Byrant, A. (2002). Re-grounding Grounded Theory. The Journal of Information Technology Theory and Application, 25-42.

Charmaz, K. (2000). Grounded Theory: Objectivist \& Constructivist Methods. In N. Denzin, \& Y. Lincoln, Handbook of Qualitative Research, 2nd edition (pp. 509-535). Sage.

Fogarty International Centre. (2008) Pathways to global health research 2008-2012 US Department of Heal th and Human Services National Institutes of Health Retrieved from https://www.fic.nih.gov/About/Documents/stratplan_fullversion.pdf

Guba, E., \& Lincoln, Y. (1994). Competing Paradigms in Qualitative Research. In N. Denzin, \&Y. Lincoln, Handbook of Qualitative Research (pp. 105-117). Sage.

Henry, J., \& Reingold, A. (2012). Prehospital trauma systems reduce mortality in developing countries: A systematic review and meta-analysis. The Journal of Trauma and Acute Care Surgery, 261-268.

Husum, H, Gilbert, M, Wisborb, T, Van Heng, Y, Murad, M. (2003) Rural Prehospital Trauma Systems Improve Trauma Outcome in Low-Income Countries: A Prospective Study from North Iraq and Cambodia. Journal of Trauma 54:1188-1196 DOI: 10.1097/01.TA.0000073609.12530.19

International Federation of Red Cross Red Crescent Societies (IFRC)(2016). International first aid and resuscitation guidelines 2016. Geneva, Switzerland

International Journal for First Aid Education (2018), retrieved from https://digitalcommons. kent.edu/ijfae/chain.html on 27 July 2019

Kato, S., Suzuki, M., Hori, S., Tokyo Fire Dept, Japan, \& Tokyo Disaster Prevention and Emergency Med Service Association. (2012). Impact of the Motive of Participants on Training Effect of CPR.

Kobusingye, O., Hyder, A., Bishai, D., Hicks, E., \& Mock, C. (2005). Emergency medical systems in low and middle-income countries: recommendations for action. Bulletin of the World Health Organization, 626-631.

Kolb, D. A. (1984). Experiential learning: experience as the source of learning and development. Englewood Cliffs, N.J.: Prentice-Hall.

Lim, S. L., Lian, T., Tan, P. T., Chan, Y. H., \& Leong, B. (2013). Public Cardiopulmonary Resuscitation (CPR) Training-Are All Lay Providers the Same?.

Lippmann, J., Livingston, P., \& Craike, M. J. (2011). Comparison of two modes of delivery of first aid training including basic life support. Health Education Journal, 70(2), 131-140.

International Journal of First Aid Education, Vol. 2 Issue 2 
McNeil, H. P., Hughes, C. S., Toohey, S. M., \& Dowton, S. B. (2006). An innovative outcomes-based medical education program built on adult learning principles. MedicalTeacher, 28(6), 527-534.

Murad, MK, and Husum, $\mathrm{H}$. Trained lay first responders reduce trauma mortality: a controlled s tudy of rurual trauma in Iraq. (2010) Prehospital Disaster medicine, 25(6) 533-539

Organisation for Economic Cooperation and Development (OECD) (2016), States of Fragility 2016: Understanding Violence, OECD Publishing, Paris, Retrieved from https://doi.org/10.1787/9789264267213-en.

Oliver, E., \& Pellegrino, J. L. (2016). Filling the voids in emergency response education: A gaps analysis. Resuscitation, 106, e56.

Pellegrino, Jeffrey L.; Oliver, Emily; Orkin, Aaron; Marentette, Don; Snobelen, Paul; Muise, Joa nna; Mulligan, Joe; and De Buck, Emmy (2017) "A call for revolution in FAE," International Journal of FAE: Vol. 1 : Iss. 1 , Article 1. DOI: 10.21038/ijfa.2017.0001

The Fund For Peace. (2017). Fragile States Index. Retrieved February 9th, 2018, from Fund For Peace: Retrieved from http://fundforpeace.org/fsi/data/

Saraç, L., \& Ok, A. (2010). The effects of different instructional methods on students' acquisition and retention of cardiopulmonary resuscitation skills. Resuscitation, 81(5), 555-561.

World Bank. (2017, August 2nd). FY18 List offragile situations. Retrieved February 9th, 2018, from World Bank: Retrieved from http://pubdocs. worldbank.org/en/189701503418416651/FY18FCSLIST-Final-July-2017.pdf 